\title{
Synoviology: a new chapter entitled to joints care
}

\author{
Beniamino Palmieri', Thierry Conrozier ${ }^{2}$, Maria Vadalà', Carmen Laurino ${ }^{1}$ \\ ${ }^{1}$ Department of General Surgery and Surgical Specialties, University of Modena and Reggio Emilia, Largo del Pozzo, \\ Modena, Italy, ${ }^{2}$ Service de Rhumatologie, Hôpital Nord Franche-Comté, 14 rue de Mulhouse, Belfort, France
}

In order to extensively investigate on the synovial membrane - related diseases, we outlined a specific medical branch named "Synoviology", targeted to the physiopathology and therapy of synovial membrane dysfunction. We searched Pubmed/Medline using the terms "synovial disease", "therapy", "synovial membrane", "joints" and "drugs", alone and combined. Selected papers from 1960 to 2015 were chosen based on their content (evidence-based quality and reliability). Clinical and experimental articles were included. Viscosupplementation with structurally different hyaluronic acid compounds, for restoration of the synovial membrane, and cartilage. The impact of other old and new medical treatments either locally or systemically administered was also included. Synoviology integrates biological, clinical and biochemical information for the progress of new therapeutic options in osteo-articular pathology.

\section{Access this article online}

Website:

http://nepjol.info/index.php/AJMS

DOI: 10.3126/ajms.v8i2.16188

E-ISSN: 2091-0576

P-ISSN: 2467-9100

Key words: Drugs, Joint disease, Synovial membrane, Therapy

\section{INTRODUCTION}

The synovial membrane is the soft tissue lining the joint cavity, periosteum, cartilages and ligaments. Synoviocytes, fibroblasts, osteoblasts, osteoclasts, leucocytes, monocytes from the microvascular network, and mesenchymal stem cells (MSCs) are involved in the articular physiology and pathology. ${ }^{1}$ They cross talk through serum proteins and Platelet-Derived Growth Factor (PDGF) signaling, cytokines, chemokines, growth factors, matrix metalloproteinases (MMPs) acting on the extracellular matrix (ECM). Locally, the bone remodeling cells modify the concentration of calcium, phosphorous and oligo elements in the joints whose chronic imbalance can induce irreversible functional impairment. ${ }^{2}$

The synovial MSCs (identified by the biomarkers $\mathrm{CD} 90^{+}$, $\mathrm{CD}_{4} 4^{+}, \mathrm{CD} 105^{+}, \mathrm{CD} 73^{+}, \mathrm{CD} 29^{+}$and $\left.\mathrm{CD} 81^{+}\right)$, actually highly focused in a therapeutic perspective, are involved in:

1 Osteophytes formation, a "fibrocartilage-capped bony outgrowth", early appearing in the osteoarthritis (OA) process (with heavy clinical impact as pain source and hypo-function).

2 Cartilages and joint membrane repair, actively involving precursor cells kinetics and metabolism from periosteum cells (fibroblasts) inducing Tumor Growth Factor $\beta$ (TGF $\beta$ ) superfamily growth factors. ${ }^{3}$

The viscous synovial fluid secreted by the synoviocytes, lubricates the cavity preventing over friction of the facing hard tissues during exercise. It harbours a few exfoliating blood cells, has peculiar chemical composition and plays a relevant viscosupplementing role, with subsequent widespread clinical use in the last 15 years (Table 1).

Individual constitution, Body Mass Index (BMI), functional motility, metabolic balance, traumas, environmental factors, hormonal constellation, organs parenchyma dysfunction, and ageing, synergistically act on the physiopathology joints background in a very complex integrated feedback.

In order to extensively and homogeneously investigate the synovial membrane and its related diseases, we conceived

\section{Address for correspondence:}

Dr. Carmen Laurino, Department of General Surgery and Surgical Specialties, University of Modena and Reggio Emilia, Largo del Pozzo 71, 41124 Modena, Italy. Phone: +390594222483, E-mail: carmen.laurino@hotmail.it

Reprints should be directed to: Prof. Beniamino Palmieri, Centro Servizi Didattici, Università degli Studi di Modena e Reggio Emilia,

Largo del Pozzo 71, 41124 Modena (MO), Italy. 


\begin{tabular}{|c|c|}
\hline Parameters & Values \\
\hline Volume & $0.13-4.00 \mathrm{ml}$ \\
\hline Relative density & $1.008-1.015 \mathrm{ml}$ \\
\hline Relative viscosity $\left(37^{\circ} \mathrm{C}\right)$ & $>300$ \\
\hline Osmolality & $292-300 \mathrm{mOsm} / \mathrm{l}$ \\
\hline $\mathrm{PH}$ & $7.31-7.64$ \\
\hline PCO2 & $4.7-7.3 \mathrm{kPa}$ \\
\hline pO2 & $<4.0 \mathrm{kPa}$ \\
\hline Potassium & $3.21-4.81 \mathrm{mmol} / \mathrm{l}$ \\
\hline Sodium & $1.30-1.40 \mathrm{mmol} / \mathrm{l}$ \\
\hline Calcium & $1.51-2.30 \mathrm{mmol} / \mathrm{l}$ \\
\hline Carbone dioxide & $19.3-30.6 \mathrm{mmol} / \mathrm{l}$ \\
\hline Chlorine & $87-138 \mathrm{mmol} / \mathrm{l}$ \\
\hline Iron & $4-7 \mu \mathrm{mol} / \mathrm{kg}$ \\
\hline Copper & $3.5-6 \mu \mathrm{mol} / \mathrm{kg}$ \\
\hline Zinc & $2.1-3.2 \mu \mathrm{mol} / \mathrm{kg}$ \\
\hline Total nitrogen & $0.84-4.0 \mathrm{~g} / \mathrm{l}$ \\
\hline Non-proteic nitrogen & $0.22-0.43 \mathrm{~g} / \mathrm{l}$ \\
\hline Urea & $120-180 \mathrm{mg} / \mathrm{l}$ \\
\hline Uric acid & $25-50 \mathrm{mg} / \mathrm{l}$ \\
\hline Total proteins & $\sim 25 \mathrm{~g} / \mathrm{l}$ \\
\hline Albumin & $6-10 \mathrm{~g} / \mathrm{l}$ \\
\hline a1-antitrypsine & $0.61-0.84 \mathrm{~g} / \mathrm{l}$ \\
\hline Ceruloplasmin & $\sim 43 \mathrm{mg} / \mathrm{l}$ \\
\hline Haptoglobins & $\sim 90 \mathrm{mg} / \mathrm{l}$ \\
\hline a2-macroglobuline & $0.22-0.41 \mathrm{~g} / \mathrm{l}$ \\
\hline Lactoferrin & $0-37-0.50 \mathrm{mg} / \mathrm{l}$ \\
\hline $\lg G$ & $1.47-4.62 \mathrm{~g} / \mathrm{l}$ \\
\hline $\lg A$ & $0.62-1.15 \mathrm{~g} / \mathrm{l}$ \\
\hline $\lg M$ & $0.09-0.22 \mathrm{~g} / \mathrm{l}$ \\
\hline $\lg E$ & $3.7-46 \mu \mathrm{g} / \mathrm{l}$ \\
\hline Enzymes & Not available \\
\hline Crystals & Not available \\
\hline Cytokines & Not available \\
\hline Glucose & $3.5-5.5 \mathrm{mmol} / \mathrm{l}$ \\
\hline Chondroitin sulphate & $40 \mathrm{mg} / \mathrm{l}$ \\
\hline Hyaluronic acid & $1.5-3.2 \mathrm{~g} / \mathrm{l}$ \\
\hline Cholesterol & Trace \\
\hline Leucocytes & $<2000 \mathrm{~mm}^{3}$ \\
\hline Monocytes & $45-50 \%$ \\
\hline Lymphocytes & $20-25 \%$ \\
\hline Macrophages & $10 \%$ \\
\hline Polymorfonuclear cells & $5-7 \%$ \\
\hline Synoviocytes & $4-5 \%$ \\
\hline
\end{tabular}

a new brand name of this specific medical and surgical branch: "Synoviology". The aim of Synoviology is pooling together different health specialties, such as rheumatology, auxology, endocrinology, clinical immunology, orthopedic, traumatology, rehabilitation/physiotherapy, gerontology, regenerative medicine, biomaterials science, radiology and instrumental imaging.

\section{MATERIALS AND METHODS}

We reviewed in vivo and clinical studies focused on the diagnosis and therapy of joint diseases and included articles published between 1976 and 2015. We searched Pubmed/Medline, using the keywords "synovial disease", "therapy", "synovial membrane", "joints" and "drugs", alone or combined. This review aims at describing how to approach the Synoviology medical branch and discusses past and future drug therapies, including hyaluronic acid, for the choice of the most appropriate viscosupplementant agent for the treatment of joint diseases.

\section{RESULTS}

The joints pathology, starting from the basic synovial membrane reactivity involvement, is a complex multietiological phenomenon enclosing degenerative, inflammatory, autoimmune, traumatic, infectious causes. A proper identification and staging of this background, will be cynically achieved by means of not invasive imaging (ultrasounds, Nuclear Magnetic Resonance, and Computerized Tomography), biochemical, genomic and proteomic investigations either from the patient serum, or synovial fluid, enclosing also exfoliative cytology and histology (synovial biopsies). Furthermore, in the clinical setting, an urgent commitment of point of care instruments (POCs) is required in order to assist the clinician decisions at the bedside. In fact, immediately after drained, the synovial exudates needs very quick and exhaustive information, in order to decide the most effective intra-cavity therapy aiming at restoring at the best the function and reducing or preventing the permanent damage, which is often progressive and invalidating.

As to the rationale treatment of Synoviology joint diseases, individually tailored therapies are really needed, through local (intracavity or dermal plasters) or systemic delivery. Intra-articular injections are a very common worldwideextended procedure with two basic main different goals: One is "viscosupplementation", with a great variety of linear and crosslinked "Hyaluronic acid (HA) compounds", and the other, "anti-inflammatory, analgesic" with steroids and local anesthetics especially after serosal effusion drainage. $\mathrm{HA}$ is certainly prevalent in terms of number of treated patients, injections schedules due to the overall safety of the molecules, growing number of published clinical trials describing not only the lubricating, but also the potential benefits on cartilage regeneration, synoviocytes protection, fibroblasts and ECM interaction. ${ }^{4}$ Anti-inflammatory and analgesics drugs are a classic, acute phase therapeutic resource, with a very old history of fast and long acting corticosteroids with facultative addition of lidocaine or other derivatives. Lidocaine, a local anesthetic was originally used to prevent the needle sticking pain of skin, subdermal layers, and synovial membrane (5). Finally, once spread into the joint cavity, it allows painless immediate motility and earlier functional recovery. ${ }^{5}$ Furthermore, local anesthetics induce chondrocyte and synovial cell apoptosis. ${ }^{6}$ 
Ropivacaine and bupivacaine had limited toxicity in human mesenchymal stem cells, but lidocaine has shown to reduce mesenchymal stem cell viability. ${ }^{7}$ Finally, the association of HA with local anesthetics reduced their cytotoxicity with bupivacaine but not lidocaine, suggesting different mechanisms of injury between the two compounds. ${ }^{8}$ Esterification of steroids, producing crystals of various sizes, is another structural option that makes them water insoluble, slowly degraded by the synovial esterase enzymes, with a delayed absorption and a more prolonged local antiinflammatory effect. ${ }^{9}$ The sodium-phosphate derivatives on the contrary, are clear, hydrophilic injectable fluids, with a short acting, but quick anti-inflammatory action. Some marketing available ampoules of steroids to be infiltrated mix the quick and long acting active principles in order to fulfill at the best the clinical needs. The advantage of these complexes is questionable, and not definitely ascertained in terms of symptoms relieve and pathologic improvement in the medium-long run.

As to the different intra-articular infiltration techniques with needles or cannula, "landmark guided" or ultrasound assisted (especially for nerve damage or hemorrhage risk joint cavity accesses, such as in the hip), and operative standard consensus has been almost reached. Subsequently, the highly safe, sterile and low discomfort standard procedures number achieved is sharply expanding.

On this basis, the impact of other old and new medical treatments either locally or systemically administered will be in Synoviology experimentally and clinically exhaustively investigated. In the curative perspective, a rationale directory of oral and injectable effective drugs for the different joints diseases (enclosing the biological response modifiers) is urgently needed. We are currently exploring, when required, a simultaneous intracavity multidrug approach to counteract each step of the joints inflammatory and degenerative process, with the advantage of lower concentrations, lower toxicity of each chemical compound injected, and of the synergistic multi drug combination rationale.

Our work hypothesis, supported by a long-standing clinical practice, is to introduce a suitable, high density, hugely crosslinked HA as basic matrix and drug releasing device, in which different active principles are physically mixed, accordingly with the individual pathology, age, weight, comorbidity, hormonal status, etc.

Nowadays, the list of the potential and already used intracavity drugs is quite wide and steadily increasing. Synoviology investigates principal mechanism of action of current drugs usually employed in synovium-affected pathologies. These drugs include anesthetics, corticosteroids, morphine, tramadol, sorbitol, mannitol, bisphosphonates, somatostatin, magnesium sulfate, vitamin $A$, anti-TNF $\alpha$ agents, methotrexate, MSCs, nonsteroidal anti-inflammatory drugs (NSAIDs), chitosan, collagen, ozone, hypertonic dextrose (prolotherapy), autologous serum injection, lubricin and vitamins. The vitamins, namely vitamin D and vitamin $\mathrm{E}$ have several literature reports but ought to be extensively investigated especially for the intracavity injections (Table 2).

\section{DISCUSSION}

Steroid drugs alter the annexin-1 protein synthesis through receptor interacting with the specific mRNA. ${ }^{10}, 11$ The subsequent inflammation breakdown is expressed in terms of reduced chemotaxis, vascular and angiogenetic reaction, soluble and cell mediated immune function with substantial reduction of cytokine cascade. In our hypothesis, the administration of steroids, even in the retard form diluted in xylocaine, does not alter the molecules aggregation or dug release, and is safe and comfortable for patients. Subchondral osteonecrosis and weakening of the capsule and ligaments is the risk of repeated local steroid injection, even if joint inflammation is the primary cause of subchondral, tendon and membranes damage. ${ }^{12}$ On these warnings, the injection schedule has to be adequately delayed every three-four months for a maximum of three injection/year.

Local anesthetics act by blocking sodium cell membrane channels and nerve conduction. Lidocaine is quicker but shorter acting and less powerful than bupivacaine. ${ }^{13}$ Ropivacaine, discovered later displayed fewer cardiotoxicity. Epinephrine prolong the anesthetic effect for 50\% due to micro-circulation constriction and delayed absorption with the warning not to be used in hypertensive patients especially using tricyclic antidepressants or imipramine derivatives of the compound. Bupivacaine, with a longer bioavailability, is widely used in muscular and joint schedules compared with lidocaine. ${ }^{14}$

Morphine and opioid derivatives individually or combined with local anesthetic, or mixed together have been successfully challenged for intracavaitary use, before, but especially after arthroscopic operations, in order to control postoperative pain. ${ }^{15}$

$\mathrm{HA}$ is one of the most fundamental element in the ECM of vertebrate tissues, and it is located in almost all body fluids and tissues (e.g. the synovial fluid, the vitreous humor of the eye, and hyaline cartilage). ${ }^{16} \mathrm{HA}$ functions as a scaffold in the ECM of tissues, where 


\begin{tabular}{|c|c|c|c|}
\hline Family & Active principles & Route of administration & Mechanism of action \\
\hline Glycosaminoglycan & Hyaluronic acid & Intra-articular & Lubrication \\
\hline Corticosteroids & $\begin{array}{l}\text { Glucocorticoids (Methyl } \\
\text { Prednisolone, Dexamethasone, } \\
\text { Triamcinolone, Betamethasone) }\end{array}$ & Intra-articular & Anti-inflammatory \\
\hline Anesthetics & $\begin{array}{l}\text { Lidocaine, Bupivacaine, } \\
\text { Ropivacaine }\end{array}$ & Intra-articular & Peripheral analgesic \\
\hline Anesthetics & Morphine, Tramadol & Intra-articular & Central analgesic \\
\hline $\begin{array}{l}\text { Free-radicals } \\
\text { scavengers }\end{array}$ & Sorbitol & Intra-articular & $\begin{array}{l}\text { Enhancement of macrophages } \\
\text { migration in the synovia, antioxidant, } \\
\text { anti-inflammatory and anti-catabolic }\end{array}$ \\
\hline Biphosphonates & $\begin{array}{l}\text { Ethidronate, Clodronate, } \\
\text { Tiludronate, Pamidronate, } \\
\text { Neridronate Olpadronate, } \\
\text { Alendronate, Ibandronate, } \\
\text { Risedronate, Zoledronate }\end{array}$ & Intra-articular & $\begin{array}{l}\text { Inhibition of the osteoclastic bone } \\
\text { resorption and delayed-type } \\
\text { hypersensitivity chronic inflammation }\end{array}$ \\
\hline Neuropeptides & Somatostatin & Intra-articular & $\begin{array}{l}\text { Systemic anti-inflammatory effect, } \\
\text { analgesic }\end{array}$ \\
\hline $\begin{array}{l}\text { NMDA receptor } \\
\text { antagonists }\end{array}$ & Magnesium Sulfate & Intra-articular, & Analgesic \\
\hline Anti-TNFa & $\begin{array}{l}\text { Infliximab, Etanercept, } \\
\text { Adalimumab, Methotrexate }\end{array}$ & Intra-articular, parenteral & Anti-inflammatory \\
\hline Staminal cells & Mesenchymal Stem Cell & Intra-articular & $\begin{array}{l}\text { Regeneration of damaged bone and } \\
\text { cartilage }\end{array}$ \\
\hline $\begin{array}{l}\text { Nonsteroidal } \\
\text { anti-inflammatory drugs }\end{array}$ & Diclofenac & Intra-articular & Anti-inflammatory, analgesic \\
\hline Polymeric compound & Chitosan, Collagen & Intra-articular & Anti-inflammatory, articular regeneration \\
\hline Gas & Ozone & Intra-articular & $\begin{array}{l}\text { antioxidant enzyme system activator, } \\
\text { immunomodulatory, anti-inflammatory }\end{array}$ \\
\hline Sugars & Hypertonic Dextrose & Intra-articular & Anti-inflammatory \\
\hline $\begin{array}{l}\text { Autologus-serum } \\
\text { injection }\end{array}$ & & Intra-articular & Anti-inflammatory \\
\hline Glycoproteins & Lubricin & Intra-articular & $\begin{array}{l}\text { Lubrication and prevention of cell and } \\
\text { protein adhesion }\end{array}$ \\
\hline Vitamins & Vitamin A & Intra-articular & Chondrocytes damage \\
\hline Vitamins & Vitamin B, Vitamin D, Vitamin C & Oral & $\begin{array}{l}\text { Potentiate the anti-inflammatory and } \\
\text { analgesic effect of intra-articular injected } \\
\text { drugs }\end{array}$ \\
\hline
\end{tabular}

it binds several matrix molecules. It has also some biological properties, such as regulation of cell adhesion and cell motility, manipulation of cell differentiation and proliferation, and providing mechanical properties to tissues. ${ }^{17}$ Several cell surface receptors such as CD44, the Receptor for Hyaluronan-Mediated Motility (RHAMM), and Intercellular Adhesion Molecule-1 (ICAM-1) interact with HA orientating, morphogenesis, wound repair, inflammation, and metastasis. ${ }^{18}$ However, in the field of Synoviology the most peculiar property of HA is to enhance viscoelasticity of some biological fluids (synovial fluid) such as vitreous humor of the eye and balancing tissue hydration and water transport. The intra-articular administration of HA is called viscosupplementation. Moreover, its unique viscoelasticity and limited immunogenicity has been adopted in several biomedical applications such as viscosupplementation in OA treatment, eye surgery, and wound regeneration and healing. The exact mechanism of action of intra-articular administration of HA is not well understood. In addition to a purely mechanical effect due to the viscosity of the products, intra-articular HA viscosupplementation is thought to provide a range of biological actions including anti-inflammatory, analgesic, anabolic and chondroprotective effects that reduce pain and disability and improve joint function. ${ }^{19}$ Clinical improvement of intra-articular viscosupplementation with HA may be achieved in a variable period from 6 months to 2 years. ${ }^{20}$ Most probably, long term efficacy of $\mathrm{HA}$ is due to the modulation of inflammatory events occurring in OA joints, by the interaction with the CD44 synoviocytes receptors. ${ }^{21}$ Compared with corticosteroids, according our experience, HA is less effective for pain relief in shortterm medications ( 2 weeks), ${ }^{22}$ but it improves analgesic property beyond the eighth week, mimicking steroid action. The delayed pain relief effect may prevent clinicians and patients from HA first choice use. However, compared with corticosteroids, HA is better tolerated. By the way, intra-articular administration of $\mathrm{HA}$ in $\mathrm{OA}$ allows to reduce oral opioid analgesics and NSAIDs, which are responsible of several side effects in the gastrointestinal system. ${ }^{23}$ 
Viscosupplementation is recommended especially for the treatment of chronic-moderate symptomatic $\mathrm{OA}$, and not for flares with joint swelling. Advantage in sport-related chondropathy has yet to be properly assessed. The ideal indication in the knee pathology seems to be moderate femorotibial OA without swelling. Results have been generally disappointing in hip OA but promising in $\mathrm{OA}$ of the ankle and shoulder (with and without rotator cuff tear). Further studies are needed to determine response profile and optimal treatment schedule, according to the joint. ${ }^{24} \mathrm{~A}$ randomized clinical trial stated that the addition of triamcinolone $(1 \mathrm{ml}, 20 \mathrm{mg})$ to $\mathrm{HA}(6 \mathrm{ml})$ from the fourth week of treatment definitely improved the pain. ${ }^{25}$

Sorbitol and mannitol have intrinsic free radical scavenger properties and promotes macrophages migration in the synovia. Sodium hyaluronate and sorbitol develop together a complex based on a dense network of hydrogen bonds forming an injectable gel. ${ }^{26}$ The oxygen free radicals neutralization by sorbitol has been proven to delay the degradation of both linear and cross-linked added HA. The antioxidant effect of sorbitol may also play a role in accelerate onset of analgesia. Mannitol, an isomer of sorbitol, showed the same antioxidant properties and has been demonstrated to protect HA against free radicals degradation.

Bisphosphonates class includes ethidronate, clodronate, tiludronate, pamidronate, neridronate olpadronate, alendronate, ibandronate, risedronate, and zoledronate. The non-nitrogenous bisphosphonates (etidronate, clodronate, and tiludronate) are metabolised in the cell to compounds that replace the terminal pyrophosphate moiety of ATP, forming a non-functional molecule that competes with adenosine triphosphate in the cellular energy metabolism. The osteoclast initiates apoptosis, leading to an overall decrease in the breakdown of bone. ${ }^{27}$ All the other cited drugs are nitrogenous bisphosphonates, and they act on bone metabolism by binding and blocking the enzyme farnesyl diphosphate synthase (FPPS) in the HMG-CoA reductase pathway (also known as the mevalonate pathway). Disruption of the HMG CoA-reductase pathway at the level of FPPS prevents the formation of two metabolites (farnesol and geranylgeraniol) that are essential for connecting some small proteins to the cell membrane. This phenomenon is known as prenylation, and is important for proper sub-cellular protein trafficking. ${ }^{28}$ While inhibition of protein prenylation may affect many proteins found in an osteoclast, disruption to the lipid modification of Ras, Rho, Rac proteins has been speculated to underlie the effects of bisphosphonates. These proteins can affect both osteoclastogenesis, cell survival, and cytoskeletal dynamics. In particular, the cytoskeleton is vital for maintaining the "ruffled border" that is required for contact between a resorbing osteoclast and a bone surface. Bisphosphonates are strong inhibitors of osteoclastic bone resorption and delayed-type hypersensitivity chronic inflammation. ${ }^{29}$ Their bone tissue affinity and anti-inflammatory properties were successfully challenged in osteoporosis and metastatic bone disease. Bisphosphonates reduce chronic inflammation and pathological mineralisation in animal arthritis models. ${ }^{30}$ Although the main bisphosphonates prescriptions have been focused on mineralization disorders associated with Paget's disease, multiple myeloma of bone and osteoporosis, less attention was addressed to their potential anti arthritic effects almost exclusively proved in the arthritic rat model. The anti-inflammatory mechanism of action of bisphosphonates may be enhanced by their high concentration into the bone matrix with subsequent toxicity for infiltrating macrophages, which play a key role in most chronic inflammatory diseases. ${ }^{31}$

Somatostatin (also known as growth hormone-inhibiting hormone $(\mathrm{GHIH})$ or somatotropin release-inhibiting factor (SRIF)) or somatotropin release-inhibiting hormone is a peptide affecting neurotransmission and cell proliferation via interaction with $G$ protein-coupled somatostatin receptors and inhibition of the release of numerous secondary hormones. Somatostatin receptors are also present in high density in synovia of patients with rheumatoid arthritis. ${ }^{32}$ Stimulation of the sciatic nerve in the rat causes release of somatostatin into the systemic circulation, which mediates a systemic anti-inflammatory effect. Somatostatin also decreases inflammation in animal models of arthritis and improves pain and joint function in osteoarthritic patients. ${ }^{33,34}$ The anti-inflammatory effects of somatostatin have been associated with suppression of neuropeptide actions.

The effect of magnesium sulfate as an $\mathrm{N}$-methyl-d-aspartate (NMDA) receptor antagonist intra-articular in reducing pain sensation, or as an adjunct to local intra-articular anesthetic, is not well known. Recent evidence suggests that NMDA receptors located in the peripheral somatic and visceral pain pathways play an important role in nociception. NMDA receptors have been found in joints as demonstrated in a rat model in a study conducted by Yu et al ${ }^{35}$ Probably, magnesium's inhibitory properties for calcium channels may play a role as well. The analgesia effect of magnesium may be the result of pharmacodynamics (causing a delayed uptake of bupivacaine from the joint) rather than a pharmacologic receptors effect. Calcium channel blockers have shown antinociceptive effects in animals and a morphine-enhancing effect in patients with chronic pain. Magnesium had preventive effects on the development of inflammation in adjuvant-induced rheumatoid arthritis rats. It has recently been found that the NMDA receptors on human synoviocytes may contribute to joint inflammation 
and destruction in rheumatoid arthritis. ${ }^{36} \mathrm{~A}$ previous study has reported the expression of NMDA receptors (NR1 and NR2) in normal human articular chondrocytes and has suggested that NMDA receptors may have a role in chondrocyte mechanotransduction. ${ }^{37}$ The same team further reported the expression of the NMDA receptor, NR2B, in OA, but not in normal chondrocytes. ${ }^{38}$ The extent of magnesium blockade depends on the structural arrangement of the NMDA receptor-channel complex, and channels containing NR2D are less sensitive to magnesium than those containing NR2B37. Magnesium deficiency upregulates interleukin (IL)-1a and IL-6, pleiotropic cytokines implicated in acute phase responses and inflammation. ${ }^{39}$

Anti-TNF $\alpha$ agents, such as infliximab, etanercept, and adalimumab are usually administered parenterally. Intra-articular therapy is appealing with the drawback of quick diffusion into systemic circulation through the inflamed synovial lining. Small molecules such as methotrexate (MTX) for instance, can be found in the opposite knee 10-15 minutes following knee injection. ${ }^{40} \mathrm{In}$ OA the injective complexity (such as the steroid - retard complexes) delays the systemic absorption, whose rate is related to the absorbing area surface ${ }^{41}$ Reports of general patient improvement following intra-articular administration of anti-TNF $\alpha$ agents suggests a significant drug clearance from the joint. Prolonged remission of resistant knee monoarthritis in a patient with spondyloarthropathy was reported following a single $100 \mathrm{mg}$ dose. Scintigraphy with $99 \mathrm{mTc}$-infliximab prior to treatment showed intense uptake in the affected knee, indicating high levels of TNF $\alpha .{ }^{42}$ Liposomal delivery of anti-TNF $\alpha$ agents in joints might be appealing, but the uptake of liposomes by macrophages might inactivate antiTNF $\alpha$ and reduce the beneficial effect. Moreover, optimal dose of intra-articular anti-TNF (alfa) agents infiltration are still not standardized and the controlled trials quite a few.

MTX is an antimetabolite inhibiting folic acid metabolism. MTX is the first choice of treatment in the therapy of juvenile idiopathic arthritis, the most common rheumatic disease in childhood that is frequently resistant to NSAID, corticosteroid intra-articular injections, and physiotherapy. ${ }^{43}$ The mechanism of action was that MTX decreases IL-8 synthesis in synovial fluid mononuclear cells, and erases IL-8 mediated granulocytes chemotaxis into the joints. Therefore, a decreased leucocyte recruitment in the synovial fluid is supposed to suppress inflammation. ${ }^{44}$ MSCs differentiate into cells of the chondrogenic lineage, and were exploited to restore the damage cartilage in $\mathrm{OA}$ patients. MSCs were first isolated from bone marrow ${ }^{45}$ and can be isolated from various mesenchymal tissues including synovium. ${ }^{46}$ It has been proposed that MSCs may be used as progenitor cells to engineer cartilage implants that can be used to repair chondral and osteochondral lesions, and as trophic producers of bioactive factors to initiate endogenous regenerative activities in the osteoarticular joint. ${ }^{47}$ Bupivacaine and other local anesthetics, e.g. ropivacaine, toxicity was detected on articular chondrocytes in cell culture and explanted cartilage samples. ${ }^{48}$ The effect of bupivacaine, ropivacaine, and morphine on tendons and tendon-derived stem/progenitor cells (TSPC) has not been evaluated in literature and remains utterly unclear. TSPC are multipotent stem cells with universal stem cell characteristics, such as clonogenicity, multipotency, and self-renewal capacity. ${ }^{49}$ Graft survival and integration process are poorly understood and dependent by multiple intra- and postoperative conditions. ${ }^{50}$ However, the viability or metabolism of the stem/progenitor cells within the tendon graft has to be preserved.

NSAIDs are widely used to reduce pain and inflammation and improve function in OA patients. ${ }^{51}$ The ability of different NSAIDs to inhibit COX, the enzyme that catalyzes the synthesis of cyclic endoperoxides from arachidonic acid to proinflammatory and other forms of prostaglandins (PG), varies: Some are strong PG synthesis inhibitors, whereas others more prominently affect non-PG-mediated biological events. Two COX isoforms have been identified (COX-1 and COX-2), and NSAIDs are now classified as nonselective or non-COX-2 selective NSAIDs and Coxibs (COX-2 selective agents). In addition, NSAIDs alter peripheral nociceptors by reducing the local concentration of these allogenic chemicals, which are activated by peripheral tissue injury. Some suggest a peripheral-central synergistic action that varies depending on the particular NSAID and on the presence or absence of an inflammatory process. ${ }^{52}$

Chitosan is a complex molecule formed by chitin, the most common polymer found in animals, which may be hydrolyzed by a strong alkali to yield chitosan, has a positive electrical charge due to amine groups, both free deacetylated and acetylated. Binding to most living tissues with negatively charged surface matrices. ${ }^{53}$ Chitosan in the musculoskeletal system has different roles. Intra-articular injection of chitosan is difficult, since it has been shown to be very inflammatory, ${ }^{54}$ although the effect depends on the type of chitosan used. The inflammatory effects probably is controlled by the migration of polymorphonuclear cells to the particles. ${ }^{55}$ The chitosan itself appears to induce osteopontin expression in leukocytes. Osteopontin is an inductor of attachment and spread of reparative cells. ${ }^{56}$ Moreover, chitosan induces collagen type II and aggrecan gene expression in a rabbit cartilage-injury model..$^{57}$ Thus, while intra-articular chitosan appears to prevent cartilage destruction and perhaps induce a reparative process due 
to cell attachment, it has also been associated with an inflammatory process, which appears to be mitigated by cross-linking of the material and exposure of chitosan to autologous blood coagulation. ${ }^{58}$ The application of chitosan appears to prevent adhesion formation in the rabbit knee following cartilage damage..$^{59}$ Early work on chitosan back to 1999 demonstrated that intra-articular injection led to cartilage overgrowth and arthrofibrosis. ${ }^{60}$ This probably depends on macrophage reaction observed when chitosan is degraded. However, in recent years several methods of bypassing this problem were developed. Injection of mesenchymal cells embedded in a chitosan matrix allows intra-articular survival of the implanted mesenchymal cells, though these cells do not seem to have participated in cartilage reconstruction. ${ }^{61}$ Indeed the use of intra-articular injection of chitosan appears to allow adhesion prevention following patellar fracture fixation. ${ }^{62}$ In addition, chitosan has been shown to improve joint lubrication when injected intra-articularly in humans. Chitosan has also been used together with a radioactive agent as a chemical synovectomy agent in humans in phase I/IIa trials. ${ }^{53}$

Ozone is a colorless peculiar smell oxygen mixture based on 3 oxygen atoms. It releases singlet-oxidizing oxygen quickly reacting with organic molecules. It is indices in nature by high voltage electric charges on oxygen. ${ }^{63}$ It is obtained by means of an electrical discharge through pure oxygen, achieving ozone concentrations between $0.05 \%$ and $5 \%$ of volume. ${ }^{64}$ Ozone therapy has been proposed through pre oxidation as antioxidant enzyme system activator, immunomodulator, and cells metabolism activator. It induces a short-lived peroxides which have been injected into cells and scavenged by glutathione peroxidase. ${ }^{64}$ Ozone failed to induce the release of cytokines and fibronectin in vitro in human alveolar macrophages, ${ }^{65}$ ruling out macrophages role in the ozone-induced inflammatory cascade. Peroxides created by ozone administration show long-term anti-rheumatoid arthritis effects, and reduce the degree of inflammation. ${ }^{66}$

Prolotherapy is a complementary and alternative medical (CAM) injection therapy for chronic musculoskeletal pain, including knee OA. ${ }^{67}$ It has been categorized as regenerative injection techniques for musculoskeletal pain. The earliest description of prolotherapy to appear in the allopathic medical literature was in 1937 in a case report for temporomandibular joint, in which the modality was called 'sclerotherapy' due to the scar-forming properties of early injectants. ${ }^{68}$ Contemporary injection techniques date from the 1950s when the more commonly used term 'prolotherapy' (from 'proliferant therapy') was adopted based on the observation that ligamentous tissue exhibited larger cross-sectional area after prolotherapy injections in animal models, ${ }^{68}$ Hypertonic dextrose is the most commonly used injectant. Injection of painful entheses with hypertonic dextrose has demonstrated clinical benefit ${ }^{69}$ and improvement in ultrasound-based tendinopathy findings in several tendinopathies. ${ }^{70}$ The processing of whole blood by incubating (typically 24 hours) at $37^{\circ} \mathrm{C}$ in the presence of medical grade glass beads that had been exposed to $\mathrm{CrSO}_{4}$ followed by harvesting, filtering the serum, is known as autologous-conditioned serum (ACS). ACS therapy consists of 6 consecutive intra-articular injections with autologous serum, after incubation of whole blood in the presence of glass beads for 6 hours. The process was first reported to increase anti-inflammatory cytokines such as IL-1Ra, IL-1, and IL-10 without significantly increasing proinflammatory cytokines (IL-1 $\beta$ and TNF $\alpha$ ). ${ }^{71}$

Lubricin is a surface-active mucinous glycoprotein secreted in the synovial joint that plays an important role in cartilage integrity. In healthy joints, lubricin molecules coat the cartilage surface, providing boundary lubrication and preventing cell and protein adhesion. Synovial fluid lubricin concentrations in injured joints are significantly lower than those found in uninjured contralateral joints. ${ }^{72}$ The direct intra-articular re-introduction of lubricin (i.e., tribosupplementation), during the peri-injury period, may offer an opportunity to preserve cartilage by reestablishing a protective covering of lubricin. ${ }^{73}$ Lubricin interacts with collagen, ${ }^{74}$ hydrophobic ${ }^{75}$ and hydrophilic surfaces via its Cterminus, ${ }^{75}$ and likely forms a loop in its mucin domain allowing the $\mathrm{N}$-terminus to also interact with the same surface. Surface bound layers of lubricin appear as both single end-grafted and double-end grafted molecules. ${ }^{76}$ The O-linked glycosylations, which decorate the mucin domain, are important in helping to create steric repulsion and hydration shells which manifest as repulsive forces working in an anti-adhesive capacity and keep cartilage asperities from direct contact. ${ }^{77}$

Hopefully, the Synoviology therapeutic choices should be planned and administered accordingly to a "metronomic" approach, that was originally adopted in the oncological area, in order to reduce the toxic impact of heavy chemotherapic burden, curing the disease with lower doses of multiple drugs. ${ }^{78}$ Interdisciplinary focus on synovia (and the around tissues) by many differently specialized doctors will reduce the gap between preclinical hypothesis and the clinical benefit outcome. In conclusion, Synoviology integrates genomic, proteomic, biochemical, immunological, morphological and clinical information for the progress of new diagnostic and taxonomic tools as well as of therapeutic options in osteoarticular pathology.

\section{Funding}

None. 


\section{ACKNOWLEDGEMENT}

None.

\section{REFERENCES}

1. FitzGerald $O$ and Bresnihan B. Synovial membrane cellularity and vascularity. Annals of the Rheumatic Disease 1995; 54(6):511-515.

2. Austin C, Hare D, Rozelle AL, Robinson WH, Grimm R and Doble P. Elemental bio-imaging of calcium phosphate crystal deposits in knee samples from arthritic patients. Metallomics 2009; 1(2):142-147.

3. Hermida-Gomez T, Fuentes-Boquete I, Gimeno-Longas MJ, Muinos-Lopez E, Diaz-Prado S, de Toro FJ, et al. Quantification of cells expressing mesenchymal stem cell markers in healthy and osteoarthritic synovial membranes. Journal of Rheumatology 2011; 38(2):339-349.

4. Siengdee P, Radeerom T, Kuanoon S, Euppayo T, Pradit W, Chomdej S, et al. Effects of corticosteroids and their combinations with hyaluronanon on the biochemical properties of porcine cartilage explants. BMC Veterinary Research 2015; 11:298.

5. Di Salvo A, Bufalari A, De Monte V, Cagnardi P, Marenzoni ML, Catanzaro A, et al. Intra-articular administration of lidocaine in anaesthetized dogs: Pharmacokinetic profile and safety on cardiovascular and nervous systems. Journal Veterinary Pharmacology and Therapeutic 2015; 38(4):350-356.

6. Rao AJ, Johnston TR, Harris AH, Smith RL and Costouros JG. Inhibition of chondrocyte and synovial cell death after exposure to commonly used anaesthetics: Chondrocyte apoptosis after anaesthetics. The American Journal of Sports and Medicine 2014; 42(1):50-58.

7. Rahnama R, Wang M, Dang AC, Kim HT and Kuo AC. Cytotoxicity of local anaesthetics on human mesenchymal stem cells. The Journal of Bone Joint Surgery. American Volume 2013; 95(2):132-137.

8. Onur TS, Sitron CS and Dang A. Co-administration of hyaluronic acid with local anaesthetics shows lower cytotoxicity than local anaesthetic treatment alone in bovine articular chondrocytes. Bone and Joint Research 2013; 2(12):270-275.

9. Sakaguchi M. A comparative study on the rate of de-esterification of dexamethasone phosphate and dexamethasone sulfate in synovial fluids. Nihon Seikeigeka Gakkai Zasshi 1981; 55(11):1621-1625.

10. Buckingham JC, John CD, Solito E, Tierney T, Flower RJ, Christian $\mathrm{H}$, et al. Annexin 1, glucocorticoids, and the neuroendocrine-immune interface. Annals of the New York Academy of Science 2006; 1088:396-409.

11. D'Acquisto F, Paschalidis N, Raza K, Buckley CD, Flower RJ and Perretti M. Glucocorticoid treatment inhibits annexin-1 expression in rheumatoid arthritis CD4+ T cells. Rheumatology (Oxford) 2008; 47(5):636-639.

12. Kang P, Xie X, Tan Z, Yang J, Shen B, Zhou Z, et al. Repairing defect and preventing collapse of femoral head in a steroidinduced osteonecrotic of femoral head animal model using strontium-doped calcium polyphosphate combined BM-MNCs. Journal of Materials Science. Materials in Medicine 2015; 26(2):80.

13. Holmdahl MH. Xylocain (lidocaine, lignocaine), its discovery and Gordh's contribution to its clinical use. Acta Anaesthesiologica Scandonava. Supplementum 1998; 113:8-12.

14. Chu CR, Izzo NJ, Coyle CH, Papas NE and Logar A. The in vitro effects of bupivacaine on articular chondrocytes. The Journal of
Bone Joint Surgery. British Volume 2008; 90(6):814-820.

15. Likar R, Schafer M, Paulak F, Sittl R, Pipam W, Schalk H, et al. Intraarticular morphine analgesia in chronic pain patients with osteoarthritis. Anaesthesia and Analgesia 1997; 84(6):1313-1317.

16. Falcone SJ, Palmeri DM and Berg RA. Rheological and cohesive properties of hyaluronic acid. Journal of biomedical materials research Part A 2006; 76(4):721-728.

17. Zheng Shu X, Liu Y, Palumbo FS, Luo $Y$ and Prestwich GD. In situ crosslinkable hyaluronan hydrogels for tissue engineering. Biomaterials 2004; 25(8):1339-1348.

18. Cai S, Xie Y, Bagby TR, Cohen MS and Forrest ML. Intralymphatic chemotherapy using a hyaluronan-cisplatin conjugate. The Journal of Surgical Research 2008; 147(2):247-252.

19. Castellacci $E$ and Polieri T. Antalgic effect and clinical tolerability of hyaluronic acid in patients with degenerative diseases of knee cartilage: An outpatient treatment survey. Drugs under Experimental and Clinical Research 2004; 30(2):67-73.

20. Navarro-Sarabia F, Coronel P, Collantes E, Navarro FJ, de la Serna AR, Naranjo A, et al. A 40-month multicentre, randomised placebo-controlled study to assess the efficacy and carry-over effect of repeated intra-articular injections of hyaluronic acid in knee osteoarthritis: The AMELIA project. Annals of the rheumatic diseases 2011; 70(11):1957-1962.

21. Yasuda T. Hyaluronan inhibits prostaglandin E2 production via CD44 in U937 human macrophages. The Tohoku Journal of Experimental Medicine 2010; 220(3):229-235.

22. Bannuru RR, Natov NS, Obadan IE, Price LL, Schmid CH and McAlindon TE. Therapeutic trajectory of hyaluronic acid versus corticosteroids in the treatment of knee osteoarthritis: A systematic review and meta-analysis. Arthritis and Rheumatism 2009; 61(12):1704-1711.

23. Bannuru RR, Vaysbrot EE, Sullivan MC and McAlindon TE. Relative efficacy of hyaluronic acid in comparison with NSAIDs for knee osteoarthritis: A systematic review and meta-analysis. Seminars in Arthritis and Rheumatism 2014; 43(5):593-599.

24. Legre-Boyer V. Viscosupplementation: Techniques, indications, results. Orthopaedics and Traumatology, Surgery and Research: OTSR 2015; 101(1 Suppl):S101-S108.

25. De Campos GC, Rezende MU, Pailo AF, Frucchi $R$ and Camargo OP. Adding triamcinolone improves viscosupplementation: A randomized clinical trial. Clinical Orthopaedics and Related Research 2013; 471(2):613-620.

26. Heisel $\mathrm{J}$ and Kipshoven $\mathrm{C}$. Safety and efficacy findings from a non-interventional study of a new hyaluronic acid/sorbitol formulation (GO-ON(R) matrix) for intra-articular injection to relieve pain and disability in osteoarthritis patients. Drug Research (Stuttg) 2013; 63(9):445-459.

27. Frith JC, Monkkonen J, Blackburn GM, Russell RG and Rogers MJ. Clodronate and liposome-encapsulated clodronate are metabolized to a toxic ATP analog, adenosine 5'-(beta, gamma-dichloromethylene) triphosphate, by mammalian cells in vitro. Journal of Bone and Mineral Research: The official journal of the American Society for Bone and Mineral Research 1997; 12(9):1358-1367.

28. Van Beek E, Lowik C, Van Der Pluijm G and Papapoulos S. The role of geranylgeranylation in bone resorption and its suppression by bisphosphonates in fetal bone explants in vitro: A clue to the mechanism of action of nitrogen-containing bisphosphonates. Journal of Bone and Mineral Research: The official journal of the American Society for Bone and Mineral Research 1999; 14(5):722-729.

29. Dunn CJ, Galinet LA, Wu H, Nugent RA, Schlachter ST, Staite ND, et al. Demonstration of novel anti-arthritic and anti-inflammatory effects of diphosphonates. The Journal of Pharmacology and 
Experimental Therapeutics 1993; 266(3):1691-1698.

30. Dougados M, Nguyen M, Caporal R, Legeais J, BouxinSauzet A, Pellegri-Guegnault B, et al. Ximoprofen in ankylosing spondylitis. A double blind placebo controlled dose ranging study. Scandinavian Journal of Rheumatology 1994; 23(5):243-248.

31. Spector WG. The granulomatous inflammatory exudate. Int Rev Exp Pathol 1969; 8:1-55.

32. Reubi JC, Waser B, Markusse HM, Krenning EP, VanHagen M and Laissue JA. Vascular somatostatin receptors in synovium from patients with rheumatoid arthritis. Eur J Pharmacol 1994; 271:371-378.

33. Silveri $F$, Morosini $P$, Brecciaroli $D$ and Cervini $C$. Intra-articular injection of somatostatin in knee osteoarthritis: Clinical results and IGF-1 serum levels. Int J Clin Pharmacol Res 1994; 14:79-85.

34. Silveri F, Lo Barco C and Brecciaroli D. Somatostatin in periarthropathies of the shoulder: Clinical effectiveness and tolerability after sub-acromial administration. La Clinica Terapeutica 1997; 148(3):75-81.

35. Yu XM, Sessle BJ, Haas DA, Izzo A, Vernon $H$ and $\mathrm{Hu}$ JW. Involvement of NMDA receptor mechanisms in jaw electromyographic activity and plasma extravasation induced by inflammatory irritant application to temporomandibular joint region of rats. Pain 1996; 68(1):169-178.

36. Flood S, Parri R, Williams A, Duance $\mathrm{V}$ and Mason $\mathrm{D}$. Modulation of interleukin-6 and matrix metalloproteinase 2 expression in human fibroblast-like synoviocytes by functional ionotropic glutamate receptors. Arthritis and Rheumatism 2007; 56(8):252325-252334.

37. Salter DM, Wright $M O$ and Millward-Sadler SJ. NMDA receptor expression and roles in human articular chondrocyte mechanotransduction. Biorheology 2004; 41:273-281.

38. Ramage L, Martel MA, Hardingham GE and Salter DM. NMDA receptor expression and activity in osteoarthritic human articular chondrocytes. Osteoarthritis and Cartilage 2008; 16(13):1576-1584.

39. Bernardini D, Nasulewic A, Mazur A and Maier JA. Magnesium and microvascular endothelial cells: A role in inflammation and angiogenesis. Frontiers in Bioscience: A journal and virtual library 2005; 10:1177-1182.

40. Bird HA, Ring EF, Daniel $R$ and Bacon PA. Comparison of intra-articular methotrexate with intra-articular triamcinolone hexacetonide by thermography. Current Medical Research and Opinion 1977; 5(2):141-146.

41. Armstrong RD, English J, Gibson T, Chakraborty J and Marks V. Serum methylprednisolone levels following intra-articular injection of methylprednisolone acetate. Annals of the rheumatic diseases 1981; 40(6):571-574.

42. Conti F, Priori R, Chimenti MS, Coari G, Annovazzi A, Valesini G, et al. Successful treatment with intraarticular infliximab for resistant knee monarthritis in a patient with spondylarthropathy: A role for scintigraphy with $99 \mathrm{mTc}$-infliximab. Arthritis and Rheumatism. 2005; 52(4):1224-1226.

43. Niehues $T$ and Lankisch $P$. Recommendations for the use of methotrexate in juvenile idiopathic arthritis. Paediatr Drugs 2006; 8(6):347-356.

44. Gao IK, Leins $C$, Bohlen $H$, Heilig B and Lemmel EM. Inhibition of interleukin-8 synthesis by intraarticular methotrexate therapy in patients with rheumatoid arthritis. Zeitschrift fur Rheumatologie 1998; 57(2):95-100.

45. Pittenger MF, Mackay AM, Beck SC, Jaiswal RK, Douglas R, Mosca JD, et al. Multilineage potential of adult human mesenchymal stem cells. Science 1999; 284:143-7.

46. Asakura A, Komaki $M$ and Rudnicki M. Muscle satellite cells are multipotential stem cells that exhibit myogenic, osteogenic, and adipogenic differentiation. Differentiation 2001; 68(5411):245-253.

47. Helliwell PS. Therapies for dactylitis in psoriatic arthritis. A systematic review. The Journal of Rheumatology 2006; 33(7):1439-1441.

48. Haasters F, Polzer H, Prall WC, Saller MM, Kohler J, Grote S, et al. Bupivacaine, ropivacaine, and morphine: Comparison of toxicity on human hamstring-derived stem/progenitor cells. Knee Surgery, Sports Traumatology, Arthroscopy: Official journal of ESSKA 2011; 19(12):2138-2144.

49. Li YH and Lin XW. The transplacental effect of methylmercury on the chromosome of embryo liver cells in rat. Zhonghua Yu Fang Yi Xue Za Zhi 1991; 25(4):220-221.

50. Ekdahl M, Wang JH, Ronga $\mathrm{M}$ and Fu FH. Graft healing in anterior cruciate ligament reconstruction. Knee Surgery, Sports Traumatology, Arthroscopy: Official journal of ESSKA 2008; 16(10):935-947.

51. Hochberg MC and Dougados M. Pharmacological therapy of osteoarthritis. Best Practice and Research. Clinical Rheumatology 2001; 15(4):583-593.

52. Ferreira SH, Lorenzetti BB and Correa FM. Central and peripheral antialgesic action of aspirin-like drugs. European Journal of Pharmacology 1978; 53(1):39-48.

53. Song J, Suh CH, Park YB, Lee SH, Yoo NC, Lee JD, et al. A phase I/lla study on intra-articular injection of holmium166-chitosan complex for the treatment of knee synovitis of rheumatoid arthritis. European Journal of Nuclear Medicine 2001; 28(4):489-497.

54. Liggins RT, Cruz T, Min W, Liang L, Hunter WL and Burt HM. Intra-articular treatment of arthritis with microsphere formulations of paclitaxel: Biocompatibility and efficacy determinations in rabbits. Inflammatory Research 2004; 53(8):363-372.

55. Usami $\mathrm{Y}$, Okamoto $\mathrm{Y}$, Minami $\mathrm{S}$, Matsuhashi A, Kumazawa $\mathrm{NH}$, Tanioka S, et al. Migration of canine neutrophils to chitin and chitosan. The Journal of Veterinary Medical Science 1994; 56(6):1215-1216.

56. Ueno $\mathrm{H}$, Murakami M, Okumura M, Kadosawa T, Uede $T$ and Fujinaga T. Chitosan accelerates the production of osteopontin from polymorphonuclear leukocytes. Biomaterials 2001; 22(12):1667-1673.

57. Zhao R, Ren Y, Sun B, Zhang R and Liang D. Experimental study on chitosan mediated insulin-like growth factor gene transfection repairing injured articular cartilage in rabbits. Zhongguo Xiu Fu Chong Jian Wai Ke Za Zhi 2010; 24(11):1372-1375.

58. Marchand C, Chen G, Tran-Khanh N, Sun J, Chen H, Buschmann MD, et al. Microdrilled cartilage defects treated with thrombin-solidified chitosan/blood implant regenerate a more hyaline, stable, and structurally integrated osteochondral unit compared to drilled controls. Tissue Enginering. Part A. 2012; 18(5-6):508-519.

59. Wang J, Yan L, Sun Y, Wang D, Dai S, Yu T, et al. A comparative study of the preventive effects of mitomycin $C$ and chitosan on intraarticular adhesion after knee surgery in rabbits. Cell Biochemistry and Biophysics 2012; 62(1):101-105.

60. Lu JX, Prudhommeaux F, Meunier A, Sedel L and Guillemin G. Effects of chitosan on rat knee cartilages. Biomaterials 1999; 20(20):1937-1944.

61. Jing $X H$, Yang L, Duan XJ, Xie B, Chen W, Li Z, et al. In vivo MR imaging tracking of magnetic iron oxide nanoparticle labeled, engineered, autologous bone marrow mesenchymal stem cells following intra-articular injection. Joint, bone, spine: Revue du rhumatisme 2008; 754(4):432-438.

62. Xu RS, Hou CL, Yin $\mathrm{CH}$, Wang YS and Chen AM. Clinical study on chitosan in prevention of knee adhesion after patellar operation. Zhongguo Xiu Fu Chong Jian Wai Ke Za Zhi 2002; 
16(4):240-241.

63. Daif ET. Role of intra-articular ozone gas injection in the management of internal derangement of the temporomandibular joint. Oral Surgery, Oral Medicine, Oral Pathology and Oral Radiology 2012; 113(6):e10-e14.

64. Hamilton JA. Hypothesis: In vitro evidence for the invasive and tumor-like properties of the rheumatoid pannus. The Journal of Rheumatology 1983; 10(6):845-851.

65. Victorin K. Review of the genotoxicity of ozone. Mutation Research 1992; 277(3):221-238.

66. Wright DT, Adler KB, Akley NJ, Dailey LA and Friedman M. Ozone stimulates release of platelet activating factor and activates phospholipases in guinea pig tracheal epithelial cells in primary culture. Toxicology and Applied Pharmacology 1994; 127(1):27-36

67. Rabago D, Slattengren A and Zgierska A. Prolotherapy in primary care practice. Primary Care 2010; 37(1):65-80.

68. Rabago D, Mundt M, Zgierska A and Grettie J. Hypertonic dextrose injection (prolotherapy) for knee osteoarthritis: Long term outcomes. Complementary Therapies in Medicine 2015; 23(3):388-395.

69. Topol GA, Podesta LA, Reeves KD, Raya MF, Fullerton BD and Yeh HW. Hyperosmolar dextrose injection for recalcitrant Osgood-Schlatter disease. Pediatrics 2011; 128(5):e1121-e1128.

70. Maxwell NJ, Ryan MB, Taunton JE, Gillies JH and Wong AD. Sonographically guided intratendinous injection of hyperosmolar dextrose to treat chronic tendinosis of the Achilles tendon: A pilot study. AJR. American Journal of Roentgenology 2007; 189(4):W215-W220.

71. Frisbie DD. Autologous-conditioned serum: Evidence for use in the knee. The Journal of Knee Surgery. 2015; 28(1):63-66.
72. Elsaid KA, Fleming BC, Oksendahl HL, Machan JT, Fadale PD, Hulstyn MJ, et al. Decreased lubricin concentrations and markers of joint inflammation in the synovial fluid of patients with anterior cruciate ligament injury. Arthritis and Rheumatism 2008; 58(6):1707-1715.

73. Flannery CR, Zollner R, Corcoran C, Jones AR, Root A, RiveraBermudez MA, et al. Prevention of cartilage degeneration in a rat model of osteoarthritis by intraarticular treatment with recombinant lubricin. Arthritis and Rheumatism 2009; 60(3):840-847.

74. Taguchi M, Sun YL, Zhao C, Zobitz ME, Cha CJ, Jay GD, et al. Lubricin surface modification improves tendon gliding after tendon repair in a canine model in vitro. Journal of Orthopaedic Research: Official publication of the Orthopaedic Research Society 2009; 27(2):257-263.

75. Chang DP, Abu-Lail NI, Guilak F, Jay GD and Zauscher S. Conformational mechanics, adsorption, and normal force interactions of lubricin and hyaluronic acid on model surfaces. Langmuir: The ACS journal of surfaces and colloids 2008; 24(4):1183-1193.

76. Zappone B, Ruths M, Greene GW, Jay GD and Israelachvili JN. Adsorption, lubrication, and wear of lubricin on model surfaces: Polymer brush-like behavior of a glycoprotein. Biophysical Journal 2007; 92(5):1693-1708.

77. Jay GD, Harris DA and Cha CJ. Boundary lubrication by lubricin is mediated by O-linked beta(1-3)Gal-GalNAc oligosaccharides. Glycoconjugate Journal 2001; 18(10):807-815.

78. Di Desidero T, Xu P, Man S, Bocci G and Kerbel RS. Potent efficacy of metronomic topotecan and pazopanib combination therapy in preclinical models of primary or late stage metastatic triple-negative breast cancer. Oncotarget 2015; 6(40):42396-42410.

\section{Authors Contribution:}

BP, TC, MV and CL-Concept and design of the study, reviewed the literature, manuscript preparation and critical revision of the manuscript; CL-Concept, collected data and review of literature and helped in preparing first draft of manuscript; BP and TC- Conceptualized study, literature search, statistically analyzed and interpreted, prepared first draft of manuscript and critical revision of the manuscript; CL and MV-Concept of study, collected data and review of study.

Orcid ID:

Prof. Beniamino Palmieri: (10) http://orcid.org/0000-0002-0871-138X

Dr. Thierry Conrozier: io http://orcid.org/0000-0003-0353-6292

Dr Maria Vadalà: (1) http://orcid.org/0000-0001-7873-5072

Dr Carmen Laurino: (10 http://orcid.org/0000-0002-3020-2338 